\title{
LGBTI-Psychosocial Services and Support Adolescents and Young People in Gauteng, Pretoria South Africa: Profiling the Psychosocial Support Services of OUT (Servicing the Lesbian, Gay, Bisexual and Transgender Community)
}

Leon Swartz* and Gerda Erasmus

Population and Development Research, National Population Unit, National Department of Social Development, Republic of South Africa, Pretoria

\begin{abstract}
The lesbian, gay, bisexual, transgender and intersex (LGBTI) case study was undertaken by the National Population Unit (NPU) to assess the activities that is run by the organisation OUT. This study form part of 10 such studies with regard to youth which was undertaken by the NPU. The study made use of a mix method approach where the qualitative aspect was the dominant method. The main aim of the study was to assess how the organisation OUT provide Psychosocial Support Services to the (LGBTI) community including HIV counselling, general lifestyle counselling as well as advice and support. This programme focuses on the psychosocial well-being of LGBTI individuals and communities. This psychosocial support services forms part of the mission and vision of OUT. The study found that LGBTI individuals still experience stigma and discrimination although the South African constitution and Bill of Rights ensure the protection of the rights of all South African citizens. The study made some recommendations in this regard.
\end{abstract}

Keywords: LGBTI; HIV/AIDS; Psychological support services; Sexual reproductive health and rights

\section{Introduction}

South Africa is one of the countries with a larger proportion of young people in the population. Approximately $78 \%$ of the country's total population constitutes young people which are below the age of 35 years. Like in many other countries, young people in South Africa are at risk of physical, psychological health and mental trauma resulting from sexual abuse, gender-based violence and other forms of physical violence, accidents, sexual and reproductive health disorders (such as sexually transmitted diseases (STDs), HIV/AIDS, unwanted pregnancies) and related complications. Different studies have also shown that in South Africa and in Sub Saharan Africa, young people engaged in early sexual debut, have multiple sexual partners and increasingly engaged in pre-marital sexual activities [1].

This research seeks to address the need to document current successful interventions directed at young people, adolescents and populations at risk, marginalized groups and those in rural areas with a view of creating an enabling environment by sharing good practices thus increasing the level of coordination and policy formulation for the sexual and reproductive health of all adolescents and young people in South Africa [1]. Specifically, there are efforts aimed at providing psychosocial support services as well as sexual and reproductive health information and services to the LGBTI youth by a number of organizations. Furthermore, the literature shows that the LGBTI youth continue to be highly vulnerable, and lack psychosocial support services as well as sexual and reproductive health services and information [2].

The organisation OUT is registered with the Department of Social Development as a Non-Profit Organisation (NPO) that provides direct health services (OUT's health services include both psychosocial and physical health services) to the lesbian, gay, bisexual and transgender (LGBTI) community including HIV testing, counselling, treatment and general lifestyle advice and support. Therefore, given insufficient mainstream service provision OUT provides direct health and mental health services to LGBTI clients. This includes targeted HIV/AIDS work, direct health services at the OUT clinic, a telephonic counselling and information line, a vibrant community centre, face to face counselling, community building programmes and spaces, and support groups [3].

OUT, especially the Psychosocial Support Services Programme in Pretoria, Gauteng, was selected to be profiled. This programme focused on the psychosocial well-being of LGBTI individuals. These services are overseen by a registered counselling psychologist and include face-to-face, telephonic and online (electronic) counselling. Most common problems clients present include relationship challenges and depression followed by insecurity regarding sexual identity and anxiety. Support groups include a youth group which focuses on themes based on challenges experienced by LGBTI youth as well as a HIV support group. Unfortunately the interest in the HIV support group declined steadily throughout the current years and a decision was made to discontinue this group and implement alternative supportive measures for HIV+ clients. Furthermore, a poster campaign was launched to raise awareness regarding psychosocial challenges faced by LGBTI individuals $[3,4]$.

\section{Literature Review}

The rights of LGBTI people in South Africa are enshrined in

'Corresponding author: Leon Swartz, PhD, Director, Population and Development Research, National Population Unit, National Department of Social Development, Republic of South Africa, Pretoria, Tel: +12 312 7954, +27 82 7701297; Fax: +27 86214 6637; E-mail: Leon@dsd.gov.za

Received July 06, 2016; Accepted August 03, 2016; Published August 10, 2016

Citation: Swartz L, Erasmus G (2016) LGBTI-Psychosocial Services and Support Adolescents and Young People in Gauteng, Pretoria South Africa: Profiling the Psychosocial Support Services of OUT (Servicing the Lesbian, Gay, Bisexual and Transgender Community). J AIDS Clin Res 7: 608. doi: 10.4172/21556113.1000608

Copyright: ( 2016 Swartz L, et al. This is an open-access article distributed unde the terms of the Creative Commons Attribution License, which permits unrestricted use, distribution, and reproduction in any medium, provided the original author and source are credited. 
the Constitution. According to the South African Constitution all its citizens are equal in the eyes of the law. LGBTI people are not an exception to this. Most countries have regarded the South African Constitution as being progressive. According to section 2, of the South African Constitution, under the heading equality, everyone is equal before the law and has the right to equal protection and benefit from the law. According to this equality includes the full and equal enjoyment of all rights and freedom. It goes on to mention that the state may not unfairly discriminate directly or indirectly against anyone on any grounds, including race, gender, sex, pregnancy, marital status, ethnic or social origin, colour, sexual orientation, age, disability, religion, conscience, belief, culture, language and birth [5].

In addition to the Constitution, the South African AIDS Charter and National Strategic Plan includes LGBTI people in its plans to mitigate HIV prevalence even though there are concerns from relevant stakeholders that the details thereof are non-existent [6]. This poses challenges and it is reported that sexual minorities endure prejudice and discrimination as a result of ignorance and misconceptions regarding the LGBTI community. South Africa is the only African country in which there are actual laws that protect the rights and freedom of gay people in the nation to exercise their beliefs and legalized same sex marriage in 2006 [7].

\section{SRH Needs of LGBTI People}

Health service delivery systems do not always recognise the diverse rights of women living with HIV, sex workers and LGBTI individuals. Health service providers also lack training and sensitivity to the specific HIV care, treatment and support, and sexual reproductive health needs and rights of women living with HIV, and LGBTI individuals - thereby making health care centres potential sites of exclusion, physical and emotional violence.

According to a study completed in Johannesburg, South Africa, gay men and lesbian women were found to have different protection needs, especially as males thought themselves more at risk for sexually transmitted infections than women due to particular sexual practices, such as anal sex. LGBTI participants stated that LGBTI reproductive health should be catered for in the same way as heterosexual reproductive health. One suggestion was that health care services not only look at whether a person is male or female, but also to their specific social context and sexual orientation and thereby assess their health service needs. Health service provision should also include the availability of different types of condoms. According to the report the South African health care setting is perceived to be 'male-unfriendly in general, and seen to cater more for women's (especially heterosexual women's) needs and requirements. A further issue that inhibits access to health services is the ridicule and the discrimination that LGBTI people face - this in turn forces them to not seek services from the public service even if they have to [2].

In the early days of the HIV epidemic, there was the belief and misconception that it was spread mainly by white homosexual men. As a result of this misconception, white gay men initially became very aware of the disease and were amongst the most educated about HIV. HIV can be spread by any two people having unprotected sex. In recent times, most HIV/AIDS education has focused on heterosexuals. Gay men and lesbian women have been neglected as a target audience for HIV/AIDS education. In the OUT research in Gauteng, one quarter of the participants who had not been tested for HIV did not know how to get tested, which indicates that more education is needed on HIV testing [3].

\section{LGBTI Individuals and HIV and AIDS}

HIV and AIDS research and programming has focused on men who have sex with men rendering other same sex practising individuals invisible in the HIV and AIDS picture. The belief that women who have sex with women are at no or low risk of HIV infection has led to the exclusion of women who have sex with women from HIV prevention efforts, access to health care services, education, treatment and research. Specific groups of women are more affected by this exclusion than others, such as women who have sex with women and are living with HIV, including those who do not identify themselves as lesbian or bisexual. This social exclusion is in many respects informed by gender inequities inherent in almost every country of the world. For this reason, any HIV prevention, treatment and care programme for women who have sex with women must work from the basis that access to knowledge and services on health is disproportionate for women and men in a context where gender inequities persist [8].

There is also a widespread misconception, characterised by exclusion from research or focus, by both women who engage in same sex relations and other stakeholders that women who have sex with women are not at risk of HIV and AIDS. In a 2002 study conducted by the Human Science Research Council (HSRC) in South Africa, 13 percent of lesbian women (aged 15-49) self-reported a positive HIV test result. While this rate is lower than seroprevalence rates for heterosexual South African women, it still represents a substantial number of people for whom no targeted HIV prevention, treatment or care services currently exist [9].

The above review illustrates clearly that despite the liberal environment that exist in South Africa the LGBTI community still experience stigma and discrimination.

\section{Rationale of the Case Study}

South Africa has been at the front of improving the quality of life and the wellbeing of young people, adolescents and populations at risk. Great strides have been made particularly in HIV prevention and treatment, psychosocial support services and access to sexual and reproductive health services.

The South African government is signatory to many international treaties, guidelines, conventions and resolutions that address sexual and reproductive health and rights as well as psychosocial problems. Among these are the Maputo Plan of Action (MPoA) on Sexual and Reproductive Health and Rights, South African Constitution, Millennium Development Goals and International Conference on Population and Development Programme. These international treaties were further complemented by South African based legislations, policies and guidelines and programmes such as National Strategic Plan for HIV, STI and TB of South Africa 2012-2016 and the National Adolescent Sexual and Reproductive Health and Rights Framework strategy to name a few. Although considerable progress that has been made in expanding access to health services through strong political leadership and development of policies, guidelines and legislation, South Africans still face challenges and obstacles in accessing comprehensive treatment, prevention and care for sexually transmitted infections, sexual and reproductive health including HIV and Aids, family planning and contraception, pregnancy, delivery, psychosocial support and counselling.

The realization of the magnitude of psychosocial and reproductive health problems the LGBTI youth face prompted the government to make it an issue of national health priority. Although Section 9 (3) 
of the South African Constitution prohibits unfair discrimination on the basis of sexual orientation, LGBTI people still face various forms of discrimination as previously mentioned. South African society is conservative, patriarchal, hetero-normative and homo-prejudiced especially I $\mathrm{n}$ rural areas. This often results in hate speech directed towards the LGBTI community and can lead to more serious offences such as the rape and murder of gay men and lesbian women.

OUT acknowledged the importance of providing direct health services to the lesbian, gay, bisexual and transgender (LGBTI) community including HIV testing, counselling, treatment and general lifestyle advice and support. Based in Tshwane (Pretoria), OUT's work takes place on local, provincial, national, continental and international levels. OUT's focus areas of work are direct health and mental health services, research, mainstreaming and advocacy

\section{Objectives of Out's Psychosocial Support Services}

To provide Psychosocial Support Services to the lesbian, gay, bisexual and transgender and intersex (LGBTI) communities including HIV counselling and general lifestyle counselling, advice and support. This programme focuses on the psychosocial well-being of LGBTI individuals and communities. The psychosocial support services forms part of the mission and vision of OUT. The focus is not only on the physical health of an LGBTI individual, but also on the psychosocial health.

\section{Key Research Questions of this Study}

Given the rationale of the Psychosocial Support Services; the primary key research questions of the study is the following:

- What type of Psychosocial Support Services/SRH interventions are undertaken by OUT?

- What has informed the provision and uptake of these services?

- What has been the impact (both by OUT and beneficiaries) of the Psychosocial Support Services and interventions on improving the sexual and psychosocial health of young LGBTI beneficiaries?

\section{Scope of the Study}

The National Population Unit, located within the Department of Social Development was responsible for conducting the research. The data collection of the: Psychosocial Support Services programme of OUT was conducted in-house by the National Population Unit.

Through the adoption of a mixed-method approach, this case study was designed to be small-scaled as to retrieve in-dep information. Consequently the proposed study does not make any attempts to generalise and reach conclusions about LGBTI-Psychosocial Support Services /interventions on a national scale.

OUT, especially the Psychosocial Support Services programme, targeted at ages 15-24 in Pretoria, Gauteng, was selected to be profiled because they provide direct health services (OUT's health services include both psychosocial and physical health services) to the LGBTI community including HIV testing, counselling, treatment and general lifestyle advice and support and they meet the selection criteria. This will be further elaborated on in the methodology section.

\section{Limitations of the Case Study}

This case study used the qualitative method in the form of focus group discussions to elicit information from OUT, particularly the Psychosocial Support Services Programme that focuses on the psychosocial well-being of LGBTI individuals. Therefore generalization of the findings for other NGOs in the country will not be feasible. The study outcome also depended on the truthfulness and openness of respondents, particularly the beneficiaries of the services as the information elicited will be considered personal and sensitive. The trustworthiness of the data may be questionable because since the study was relying on self-reported information (by key informants), therefore, information bias is likely to occur due to over or under reporting on the attitude and perceptions as well as barriers to access to SRH services and Psychosocial Support Services among the LGBTI youth.

\section{Research Methodology}

The following research approach was adopted.

\section{Research design}

A mixed research method design was used for the study. The mixed research method is the preferred design for this good practice study as it seeks to understand the uptake and access to LGBTI-Psychosocial Services and Support to Adolescents and Young People in Gauteng in the form of a good practice case study amidst the backdrop of the specific social contexts.

\section{Sampling and recruitment}

The sample that was drawn by using the non-probability purposive sampling method participated voluntary in the study. According to Greenstein et al. this sampling method is used to target particular individuals and categories of people for investigation. This study is not meant to be representative; therefore the sampling was sufficient [10].

OUT was selected to be profiled because they meet the selection criteria for inclusion as a good practice case study to LGBTIPsychosocial Services and Support to Adolescents and Young People. The criteria for selection are the following: Firstly criteria on delivery of client-centred care that is sensitive to each adolescent's culture, ethnicity, community values, religion, language, educational level, sex, gender and sexual orientation; Secondly criteria on confidentiality; criteria on referral and follow-up systems; criteria on record keeping; criteria on monitoring and evaluation; criteria on leadership; Thirdly, criteria on practice; Fourthly, criteria on skills and training; Fifthly criteria on access and service provision; and lastly, criteria on advocacy and information sharing. (At the criteria for selection, the following scale was used; Inadequate $=1$, Fair $=2$, Good $=3$, Excellent $=4$ ) [2].

Respondents were grouped into two main groups. Each of these groups has a specific sampling strategy in accordance with the purposive sampling technique. These groups have been classified as follows: Primary target group - Adolescents and young people aged between 10 and 24 who are the beneficiaries of the psychosocial services of OUT in Pretoria and Secondary target group - Key informants in the form of a, psychologist, health manager and the Director of OUT in Pretoria.

\section{Research methods}

Three Key informants who are implementers of the psychosocial services of OUT in Pretoria as well as the CEO of OUT were interviewed. Four individual interviews were completed with beneficiaries of the psychosocial services of OUT, aged between 15 and 24. The individual interviews were done due to the sensitive nature regarding LGBTIs. The focus group guide was adapted as an interview guide in this instance. 


\section{Data Capturing and Data Analysis}

\section{Qualitative methods}

The semi-structured interviews and focus groups were transcribed and manually analysed using thematic analysis. Thematic analysis has been identified as the method of making sense of the qualitative data as it emphasizes interpretation and the discovery of meaning [11]. Central themes and patterns of difference and similarity will be elicited and explained in the context of the research findings and literature. The qualitative method was the main method of investigation.

\section{Quantitative methods}

To compliment qualitative data, the quantitative data yielded from the brief demographic questionnaire were analysed using the SPSS software package. Noting that the study follows a non-probability sampling method and that this is not a representative study, the data will be presented descriptively in the form of frequencies and percentages. Lastly the results cannot be generalized.

\section{Discussion of Findings}

The following discuss the findings starting with a short overview of the quantitative data.

\section{Profile of the recipients of the psychosocial support services}

Population group: The majority of the recipients were Black Africans (75\%), followed by White (25\%).

Age distribution of recipients: The minimum age of the recipients was 22 and the oldest recipient was aged 23 . Fifty percent of the beneficiaries were 22 years old and $50 \% 23$ years old.

Educational level of recipients: The majority of the recipient $s$ (50\%) had a diploma; one had a secondary education and 1 recipient an honours degree.

All the beneficiaries interviewed were male.

The following section gives an overview of the qualitative findings.

\section{Qualitative Findings}

Firstly, the Advocacy \& Mainstreaming Programme of OUT aims to ensure legal equality and translating it into day to day experiences. It includes law reform, sensitisation of mainstream service providers and empowering LGBTI people to claim their rights. The health and wellbeing programmes offered by OUT include: Psychosocial Support Services/Programme; Barrier Method Distribution Service; OUT Clinic; Bridging Gaps Programme; Peer Education Programme; Editorial submissions and the Love not hate campaign. OUT also offers training to mainstream service providers and other interested parties. The training assists individuals to understand themselves as sexual beings. OUT also educate the communities on LGBTI and sensitive issues. OUT conducted a total of 45 sensitisation trainings in six provinces in the 2012/2013 financial year. These provinces include Gauteng, Limpopo, Eastern Cape, Northern Cape, Kwa Zulu Natal and the Free State. A total of 885 health care providers, including nurses, medical doctors, social workers, psychologists and counsellors, HCT counsellors, facilitators, researchers, other service providers, peer educators and outreach workers from the public health sector, universities, NGOs (including LGBTI) and other sectors were reached (OUT annual report, 2012-2013).

The rights of LGBTI people is supported by the constitution of
South Africa which is one of the most important policies and guidelines that inform the operations of OUT. OUT worked in consultation with the Department of Health and the SA National AIDS Council around the national HIV/AIDS plans and the operationalising thereof. As a Sector, OUT developed an operational plan to achieve relevant targets on the Government's National Strategic Plan on HIV/AIDS and TB [6]. They also started participation in the Department of Justice's Task Team (TT) on Gender and Sexual Orientation based Violence against LGBTI people. The organisation is a member of the Hate Crime Working Group - an umbrella body focusing on hate crime legislation, research, and highlighting issues around hate crimes amongst the general public. Furthermore they also closely work with the Department of Labour. OUT uses international guidelines to support their programmes. Findings of studies that have been conducted in the Netherlands regarding health services and access to health services has been used by OUT to inform the way they work and also tailor make their programmes. The organisation is a member organisation of the International Lesbian and Gay Association (ILGA). One of OUT's biggest strengths is their networks that have been established through many years of work [12].

OUT has an individual client register that has to be compiled and completed by the clinic nurse. They also use a monthly tool to track all the distributions, i.e. all the commodities, condoms, lubrications, safer sex packs, pamphlets, etc. Their peer education outreach also keep client registers of each client.

For all the psychosocial services, OUT uses a "tick sheet" that they complete after they have any contact with any client for example face to face counselling, electronic contact or a telephonic contact. The organisation complete all the information, what the contact were about, whether it was coming out or relationship problems, psychological (depression or anxiety), victimisation, etc. These monthly sheets (reports) are distributed to funders.

Evident from the findings is that there's a strong referral structure in place at OUT and referrals are made by the organisations staff on a regular basis. They also have a referral tracking system where they follow up if the referral was successful. OUT also accept and refer young people from other countries that seek asylum in South Africa because of their sexuality. Referrals are made depending on what is the need of the beneficiaries, for example they refer to PASOP in Cape Town, Lawyers for Human Rights etc.

Participants surveyed said that the LGBTI youth frequently encounter numerous challenges and they feel isolated, confused, depressed, and fearful as they attempt to navigate their emerging awareness of their sexual and/or gender identity. According to the key informants surveyed the LGBTI youth within the ages 10 to 24 years, the challenges are largely about acceptance, people are struggling with their sexuality. Due to lack of information society keeps making them feel bad about this part of their lives and that of course makes them further vulnerable to substance abuse, in terms of coping, with the pressures and discrimination. Worldwide studies have shown South Africa is incredibly homophobic. In South Africa $85 \%$ of the society still say it's not acceptable at all, whereas in Holland which is more open and liberal, already like $70 / 75 \%$ say it is acceptable. It's not just the issue of discrimination, it is also the issue of the norm of heterosexuality, everyone just assumes everyone is heterosexual and that in itself is detriment [4].

Evident in the findings is that LGBTI (lesbian, gay, bisexual and transgender) people are target of general violence and crime. These 
Citation: Swartz L, Erasmus G (2016) LGBTI-Psychosocial Services and Support Adolescents and Young People in Gauteng, Pretoria South Africa: Profiling the Psychosocial Support Services of OUT (Servicing the Lesbian, Gay, Bisexual and Transgender Community). J AIDS Clin Res 7: 608. doi: 10.4172/2155-6113.1000608

Page 5 of 7

findings have also been found by Nel and Judge [13]. According to the authors LGBTI people are targets of general violence and crime. As LGBTI people in South Africa are stigmatised for their perceived sexual and/or gender 'deviance', they are also frequently discriminated against, through criminal acts, because of their sexual orientation and/ or gender identity. Further research suggests that LGBTI survivors of hate crimes showed significantly more signs of psychological distress than did LGBTI survivors of comparable non-bias-motivated crimes. These feelings can last up to five years for LGBTI victims of hate crimes, especially if the person does not receive psychological help [4].

Participants surveyed believed that there is a trend of an institutionalized homophobia in the communities/areas that OUT serve in Pretoria- whereby institutions such as families, schools, police and justice departments, clinics, churches, workplaces, and youth clubs discriminate against LGBTI people. These findings have also been found by a study conducted in Johannesburg, March 2012 whereby some children were reported to have been denied access to the schools after being classified as LGBTI people. The Human Rights Watch also found discrimination over and above the physical and sexual violence and the lack of redress. They said those participants they interviewed had been discriminated against in the fields of education and employment and denied services. Lesbians and transgender people who did not follow conventional patterns of dress and appearance and lacked family support were particularly vulnerable to abuse and discrimination [2].

According to the key informant's initiatives to address social and health challenges should be prioritized, more efforts should be done to mainstream service providers and other interested parties. OUT still face lots of resistance in communities against LGBTI people. Recent research by Cochran et al. also has shown that LGBTI people experience lack of integration with communities they live in, social isolation and problems of self-acceptance and/or limited access to, formal or informal mechanisms of social/psychological support [14]. LGBTI people have greater psychiatric morbidity than their heterosexual counterparts and that this excess morbidity is related to exposure to stressors, such as prejudice, discrimination and violence. The curriculum especially in the schools should more be influenced, where in Life Orientation human sexuality should be injected in so that people can know that there's diversity within sexuality. This will shift huge barriers that separate people. Evident from the findings is that OUT also addresses social and health challenges through one of their programmes where they collaborate with tertiary institutions and other African countries. OUT arrange dialogues, they invited experts from the mental health field from African countries to participate in the dialogues. Through these dialogues OUT hoped that they influence people how they think and that they will take it back to their countries again [15].

The psycho social support services of OUT started in 1994. It was the first service they had in the form of telephone counselling. Over the years it changed to client's direct needs and demands. In the beginning they had a therapeutic support group for gay men, a group for lesbian mothers as well as a HIV positive group. Evident from the findings is that there's also a strong referral structure in place for the psychosocial services of OUT. They provide all the psychosocial counselling at OUT but if realise that a client needs to be referred, the organisation have a reference list, which entails a resources list of psychologists, psychiatrists that they can refer a client to. They only refer when they realise that there's personality disorders or maybe serious depression, anxiety, mental health issues, etc. OUT's psychosocial support services are equipped to cater for the specific issues that may face lesbian/gay people in relation to: sexual behaviour; relationships and legal issues [16].

The findings of the research consistently indicate that the OUT website and telephonic counselling are most important sources for SRHR information among LGBTI young people. Young LGBTI people also use the psychosocial support services offered, the OUT clinic and youth groups to source health information and track issues they are concerned about. Beneficiaries make sometimes use of the public hospitals/clinics in Pretoria but the public hospitals/clinics in Pretoria are not LGBTI youth friendly compare to OUT. Barriers to access hospital and the clinic may sometimes include: lack of transportation and discrimination against LGBTI persons. According to the beneficiaries they prefer to go to OUT for their psychosocial support and SRH services due to the confidentiality and friendliness at OUT [16].

The LGBTI youth surveyed said that the quality of services OUT rendered is exceptional. The staff of OUT support them with difficulties they experienced regarding relationship challenges, depression, HIV status, insecurity regarding sexual identity, anxiety, etc. OUT services and especially the psychosocial support services of OUT continue to confirm (through usage and uptake) that they are indeed responding to the needs of their clients and communities. Additionally, they have shown leadership with the high quality of and demand for their expertise in training. The organization play a leading role in promoting the psychosocial support and SRHR services among all young LGBTI people and the services offered are inclusive of all applicable groups e.g. young persons with disabilities, illiterate people, and different language groups etc. According to the beneficiaries of the psychosocial support services of OUT has supported them to come to terms with their sexuality and make informed choices about their sexual and health-seeking behaviour. The service enable them as the LGBTI youth to understand health risks; increase their SRHR knowledge, build selfesteem, skills and confidence and motivate them to keep to healthy behaviours; and improve their relationships with their parents, families and the community.

One of the areas of improvement of the service according to the key informants surveyed is that there is a need for more funding for the female clientele. An ongoing challenge in OUT is marketing of all the services; reaching enough LGBTI people. Staff capacity is sometimes a challenge. Due to that beneficiaries felt that their preferred psychologist/ peer educator is not always available and that can be a hindrance. Beneficiaries surveyed believed that OUT must employ more staff to go out to the communities and give them psychosocial support there especially for those people who find it difficult to come to OUT. Beneficiaries recommend that OUT offers their services and support also on a Saturday.

The psychosocial support services of OUT always keep the beneficiaries' sensitive health care issues private. The imperative need to guard the LGBTI youth's confidentiality extends to every staff member of OUT. According to the key informants OUT staff is very attentive that the LGBTI youth can be especially concerned about confidentiality regarding their sexual orientation or gender identity. They may be put in considerable danger by being deliberately or accidentally 'outed'. Confidentiality is very crucial for them as expressed by the following quote:

"The positive aspects of the face to face counselling which I accessed are that you only spoke to one psychologist and he was also a sound board for me. I had a friend that I could talk to about my problems but 
you cannot always burden your friend about your problems, you want to be with your friend and be happy, do good things, have a good time not complain about your problems all the time.

This is what happened until I decided to come here at OUT. I started sharing my problems with the psychologist. The face to face counselling was and is still exceptional for me."

\section{Beneficiary: OUT}

Provision of youth-friendly services is a critical part of ensuring LGBTI young people receive the care they want and need, whether it is sexual or psychosocial support and health services. Access to such services helps LGBTI people to lead healthy and successful lives. The report provides seven essential components of OUT youth-friendly services, namely confidentiality, OUT staff are professional and treat the LGBTI young people with respect and dignity, OUT's comprehensive service model, OUT's aim for a diverse, well-trained staff, swift service to the LGBTI youth, free cost services and partnerships between parents, their LGBTI children and OUT staff. The following quote illustrate some of this component:

"My psychologist assured me that all the information will be kept confidential. I am confident that everything that I discuss with him is kept confidential, that is why I find it so easy to open up to him. I know that he will not discuss my personal issues with anyone".

Studies have shown that adult-focused programs and workshops can greatly strengthen parents' skills, willingness, and determination to have conversations with their LGBTI teens about their sexual identity. According to the key informants there are two issues with regards to coming 'out'. First of all a LGBTI person needs to find self-acceptance. To do that, OUT supports a client through the process of accepting who they are, their sexual identity or general identity. However, a very important part of the process is that family members, especially parents find it difficult to accept that their child is gay or lesbian and therefore OUT supports family members of LGBTI teens and promoting partnerships with their parents. OUT support the parents to accept their LGBTI teens and their sexuality through workshops, online counselling etc.

The psychosocial services of OUT has achieved a lot since there period of existence. Over the last 17 years, OUT has developed a comprehensive service delivery model. This model combines and links macro work (policy inclusion and others) with the micro work of delivering services and the building of on-going expertise. OUT's comprehensive service model included preventative work as well as the provision of care and treatment. These services were provided through the OUT clinic, psychosocial support programme, barrier method programme, community outreach and online interventions. This psychosocial support services proved to be a huge success in Pretoria. In the 2012/2013 financial year there were 63895 users making use of the online interventions; 29399 womyn2womyn users and 34496 men2men users. In the 2012/2013 financial year 830 clients access the psychosocial services. 279 clients accessed the face-to-face-to face counselling, 241clients the electronic interventions, 157 the youth group, 133 telephonic counselling and 20 the HIV support group. Face-to face and online counselling saw a consistent increase compared to the 2011/12 period. A total of 183602 individuals were reached during the 2012/13 financial year. On a macro level, OUT worked with partners to develop a new national hate crime programme. They also started the development of a new integrated training manual that incorporates the issues faced by Men who have Sex with Men (MSM), people who inject drugs and sex workers. OUT worked closely with the National Department of Health in this development. OUT was also nominated to host the Secretariat of the South African National AIDS Council's LGBTI Sector. As a Sector, they developed an operational plan to achieve relevant targets on the Government's National Strategic Plan on HIV/AIDS and TB [6].

The Annual report of OUT stated that they reached almost 13000 clients with peer contacts on risk reduction and HIV risk reduction and promoting OUT services in the 2012-2013 financial year. Strong lasting collaborations were formed between Funders and OUT, creating a platform for activities to reach the LGBTI youth. OUT staff demonstrated in the findings that it is possible (and indeed necessary) to impart SRHR information and provide psychosocial support services to the young LGBTI people in Pretoria. OUT has done a lot of collaborative research with other research institutions. OUT trained mainstream health care workers; over 45 sessions took place and an estimated 900 people were trained. OUT assisted Bonela (HIV prevention and human rights based NGO in Botswana) with a two day training workshop to understand human sexuality and to implement a peer education programme [16].

Lastly, while impact studies are not yet done, findings suggest that OUT staff from the psychosocial support services was successful in supporting the young LGBTI people in Pretoria to cater for their own specific issues that they may face in relation to their physical and psychosocial sexual health; sexual behaviour; general lifestyle; relationships and legal issues. Sexual and Reproductive Health and Rights (SRHR) play a major role in the lives of LGBTI people enabling them to live freely and responsibly on all aspects of their sexuality. Sexual health is a fundamental human right and requires a positive, respectful approach to sexuality - free of intimidation, discrimination and violence. Programmes, policies and laws conducive to sexual wellbeing and non-discrimination are required for sexual health to be attained and maintained. Through the psychosocial support services of OUT, the LGBTI beneficiaries develop confidence, knowledge and skills needed to make positive changes to protect their physical and psychosocial sexual health. The following quote illustrate this:

"Successes yes, if I think about specific cases of clients without giving any personal information and bridge the confidentiality. We've had clients who found out that they are HIV positive from our clinic, they had been referred directly to access the psychosocial services and we have successfully guided and supported them throughout the whole process. It's basically a grieving process that they go through because it's a loss of health and in some cases people feel that they lose their future, their goals, they lose sight of their dreams because to them it feels like a death sentence. And although the messaging has changed a lot, we do find that it's still true that when a person finds out he/she is HIV positive is still a big shock and they still have to deal with all those feelings. We have very successfully guided people through that whole process, right through from finding out, to acceptance, and to start adjusting their lifestyles and start to making new goals and finding new dreams for themselves." Key informant: OUT.

\section{Challenges}

The following challenges were observe during the study:

Secure and stable funding is a key aspect of sustainability and expansion of the psychosocial support services. It iscritical that community programmes start attracting more South African Government funding for longer term financial sustainability. Staff capacity is sometimes a challenge. OUT is a small organisation. Previously they used to have 22 staff members but it had been reduced. People left for other positions 
Citation: Swartz L, Erasmus G (2016) LGBTI-Psychosocial Services and Support Adolescents and Young People in Gauteng, Pretoria South Africa: Profiling the Psychosocial Support Services of OUT (Servicing the Lesbian, Gay, Bisexual and Transgender Community). J AIDS Clin Res 7: 608. doi: 10.4172/2155-6113.1000608

Page 7 of 7

and it was decided not to replace all those positions. They are still able to manage, but it means that they could maybe take more clients in if they were a bigger organisation. Late payments from some funders. As a result of this certain OUT programmes could not start on time and OUT has a shorter period to reach targets.

During OUT's hate crimes programmes, one of the challenges they experience is that hate crimes are still underreported often due to victim's fears that they will not be taken seriously or will be revictimised. There is a need in South Africa to explore methods of ensuring that those who perceive themselves to be victims of hate crimes feel comfortable enough to report these crimes to the police and have faith that these will be followed up effectively. More research is needed on LGBTI issues. There are almost no national 'official' studies where the interests of LGBTI people are included. Within the LGBTI sector itself, there is limited capacity to conduct relevant research especially if the aim of the research is to obtain valid, reliable and representative data. Discrimination and violence against people due to their actual or perceived sexual orientation and/or gender identity continues. OUT acknowledged that there is limited availability of programs and services that are tailored for the LGBTI youth and their families and that also present a challenge. LGBTI youth may fear disclosing their identities and, as a result, may be inhibited from seeking the support and therapeutic resources they need. Youth who are afraid to be open about their identity, or "come out," may be less likely to report their experiences and needs to providers and others in a service system.

\section{Recommendations}

The study recommends the following:

More extensive campaigns should be devised which talk about preventing homophobia within South Africa and ensuring a safe and healthy environment for everyone, irrespective of sexual orientation. Work aiming to increase the acceptance of LGBTI communities should be embraced by gender organisations. As work aiming to address homophobia is linked to gender work, gender organisations should always promote the rights of LGBTI people as part of their mandate. Promote more community awareness of the rights of LGBTI people. Strengthen documentation and monitoring of the experiences of LGBTI people. Language must always be an important consideration when designing programmes for LGBTI well-being. Policies and interventions should consider the fact that the young people are dependent on family and friends and information should be shared in a manner sensitive to these considerations. By providing more information on LGBTI issues to the extended family and friendships circles, better understanding could be facilitated and the levels of acceptance of LGBTI people can increase. LGBTI youth organisations should work with the parents of LGBTI young people on a regular basis to provide guidance to them on how best to support their children [17].

\section{Conclusion}

OUT has been in existence for almost 20 years and evidence confirm that they are dedicated in building healthy and empowered LGBTI communities in South Africa and internationally, while reducing heterosexist and homophobia in society. OUT has developed a comprehensive service delivery model and this report reflects their work on many levels. OUT achieve their objectives by implementing a range of activities in respect of health, broader advocacy and mainstreaming. OUT's direct services continue to confirm (through usage and uptake) that they are indeed responding to the needs of their clients and communities.
The psychosocial services model of OUT is sustainable and could be adapted in any other organisation. This model is already being used as a benchmark by one of OUT's funders and by other organisations nationally and in the Southern African region. OUT has organisations visiting them to be trained about the psychosocial support services offered at OUT. OUT staff recommend that this model of psychosocial support services, whether it's counselling or online be replicated in other areas. It's very effective because it's also very simplistic. The energy and dedication of OUT staff is of an invaluable resource for the LGBTI people in the diverse communities they serve in Pretoria. The psychosocial services model serves as an excellent model of good practice in meeting the challenges faced by the lesbian, gay, bisexual, transgendered and intersex adolescents and young people with respect to psychosocial, SRHR and HIV services.

\section{Acknowledgement}

We would like to thank the UNFPA South Africa for their financial contribution and the organisation OUT that gave us permission to undertake the research and write up the case study.

\section{References}

1. Department of Social Development (2016) Population policy 15 year review synthesis report, Pretoria.

2. National Association of People Living with HIV and AIDS (2012) The experiences and needs of LGBTI living with HIV in Johannesburg, South Africa.

3. Van Dyk D, Matlou J (2011) Understanding Human Sexuality. OUT 1-81.

4. Mayock P, Bryan A, Carr N, Kitching K (2008) Supporting LGBTI lives: A study of mental health and well-being. Gay and Lesbian Equality Network (GLEN).

5. Republic of South Africa (1996) South African Constitution. Government Printers, Pretoria.

6. Department of Health (2011) National Strategic Plan on HIV, STIs and TB 2012 - 2016. Government Printers, Pretoria.

7. Republic of South Africa (2006) Civil Union Act 2006. Government Printers Pretoria.

8. UN Women (2013) Silenced and forgotten. HIV and AIDS agenda setting paper for women living with HIV, sex workers and LGBTI individuals in southern African and Indian Ocean states. The Open Society Initiative for Southern Africa.

9. HSRC (2002) Nelson Mandela/HSRC study of HIVIAIDS: South African national HIV prevalence, behavioural risks and mass media: Household survey 2002. HSRC Library.

10. Greenstein R, Roberts B, Sitas A (2003) Research methods manual, introduction to quantitative methods. Quantitative Research Methods 1-39.

11. Braun V, Clarke V (2006) Using thematic analysis in psychology. Qualitative Research in Psychology 3: 77-101.

12. OUT (2006) Lesbian/Gay/Bisexual/Transgender (LGBTI) Well-being annual report 2005-2006. OUT.

13. Nel JA, Judge M (2008) Exploring homophobic victimisation in Gauteng, South Africa: Issues, Impacts and Responses. Acta Criminologica 21.

14. Cochran SD, Sullivan JG, Mays VM (2003) Prevalence of mental disorders, psychological distress and mental health services use among lesbian, gay and bisexual Adults in the United States. J Consult Clin Psychol 71: 53-61.

15. OUT (2016) Book of Learners. OUT, Pretoria.

16. OUT (2012) Brochure-LGBTI Well-Being. OUT Pretoria.

17. OUT (2012) Lesbian/Gay/Bisexual/Transgender (LGBTI) Well-Being. Annual Report 2011/12. Pretoria: OUT. 